\title{
Rationale and Study Design: The Screening of Congenital Heart Disease by Cardiac Auscultation and 12-Leads Electrocardiograph Examination in First-grade Elementary School Children in Province of Yogyakarta, Indonesia
}

Lucia Kris Dinarti ( $\nabla$ kris_dinarti@ugm.ac.id) Universitas Gadjah Mada Fakultas Kedokteran https://orcid.org/0000-0002-4011-2184

Anggoro Budi Hartopo

Universitas Gadjah Mada Fakultas Kedokteran

Indah Kartika Murni

Universitas Gadjah Mada Fakultas Kedokteran

Vera Christina Dewanto

Universitas Gadjah Mada Fakultas Kedokteran

Armalya Pritazahra

Universitas Gadjah Mada Fakultas Kedokteran

Muhammad Reyhan Hadwiono

Universitas Gadjah Mada

Dyah Wulan Anggrahini

Universitas Gadjah Mada Fakultas Kedokteran

Research article

Keywords: Congenital Heart Disease, Screening, Electrocardiography, Indonesia

Posted Date: October 4th, 2019

DOI: https://doi.org/10.21203/rs.2.15479/v1

License: (c) (i) This work is licensed under a Creative Commons Attribution 4.0 International License.

Read Full License 


\section{Abstract}

Background Congenital heart diseases (CHD) cause declining of functional capacity, cyanosis, arrhythmia, stroke, and death in adulthood. The screening for congenital heart disease in children has not been established in Indonesia. This results in a relatively high prevalence of uncorrected CHD in adulthood, who mostly have developed pulmonary artery hypertension. The screening program by cardiac auscultation and electrocardiography (ECG) in schoolchildren has been proven to be feasible in developed countries, which may also be feasible in Indonesia.Aim This study was planned to test and assess CHD screening methods based on electrocardiography examination in school children.

Methods We conducted a screening program in first grade elementary school children in the Province of Yogyakarta, Indonesia. The schools were determined by purposive sampling. Trained general practitioners in community health centers participated in the screening. The physical examinations were done, which focused on cardiac auscultation and ECG examination. Those who had abnormal findings underwent trans-thoracic echocardiography to confirm the CHD.

Results We collaborated with local governments in recruiting the participating community health centers and elementary schools. A total of 130 elementary schools from 5 districts in Yogyakarta Province were recruited, all without prior information on students' presentation of symptoms.

Conclusions This study is the first screening program that focuses on heart diseases in elementary school students in Indonesia. The success and feasibility of this program will give a valuable impact on preventing CHD complications during adulthood.

\section{Background}

The importance of early detection of congenital heart disease (CHD) has been emphasized in many developed countries. CHD is a congenital defect which ranks amongst the main causes of death in the first year of human life. ${ }^{1}$ Some forms of CHD can survive into adulthood without obvious symptoms. A $\mathrm{CHD}$ is caused by an abnormality of heart development during embryogenesis and most of them happen due to genetic defects. ${ }^{2}$ There are three types of CHD commonly found, namely ventricle septal defect (VSD) in $30.9 \%$, atrial septal defect (ASD) in $9.8 \%$ and patent ductus arteriosus (PDA) in $9.7 \%$ of total $\mathrm{CHD} .3,1,4$ In developed countries, these three types of $\mathrm{CHD}$ can be detected during pregnancy and childhood; and therefore, early managements such as operative and non-operative treatments to close the defects could be done successfully. 5,6

If left uncorrected, CHD could induce excessive circulation inside pulmonary vessels and increase right heart volume load. Increasing pulmonary vascular pressure and resistance, which resulted from histopathological changes of pulmonary arteries, may cause pulmonary arterial hypertension (PAH). PAH can modify the course of circulation flowing through the defect from the right to left side of the heart (Eisenmenger Syndrome). The changes of circulation flow may cause declining of functional capacity, 
cyanosis, arrhythmia, stroke, and even death in adulthood. ${ }^{7,8}$ The PAH incidence in adult ASD is $15-19 \%$ and can commonly occur during the fifth decade of life, if closures were not performed. ${ }^{9,10,11}$ Meanwhile, the prevalence of Eisenmenger Syndrome in CHD patients varies between 2-6\% based on previous registry. $.10,11,12$ Finding of such late cases would cause many health problems, which are high-cost medication and low quality of life as well as reduced productivity of patients. Therefore, early detection is an important factor in preventing CHD complications.

In Indonesia, screening for heart abnormalities in children has not yet been systematically established. This affects the number of undiagnosed and uncorrected CHD in adulthood. Since 2012, at the Faculty of Medicine Universitas Gadjah Mada and Dr. Sardjito General Hospital Yogyakarta, a CHD registry has been conducted on adult patients (described as Congenital HeArt Disease in adult and Pulmonary Hypertension (COHARD-PH registry). Until 2018, there had been more than 800 adult patients with CHD registered, among whom $68.7 \%$ had PAH and Eisenmenger Syndrome at relatively young age. ${ }^{13}$ One of the reasons of high prevalence of PAH in adult CHD patients is currently there is no early detection programs for heart defects in Indonesia for young children, in which most of the children with no or mild symptom would be under-diagnosed. Until today, early health screening done in Indonesian young children does not specifically detect heart abnormalities. In developed countries, for example Japan, early detections for CHD have been performed in stages starting from pregnancy, then continued during newborn, infant and childhood. ${ }^{6}$ From this type of screening program, CHD can be identified as early as possible before severe symptoms manifest, and corrective treatment can be performed. In Japan, the success of this screening could drastically decrease the number of $\mathrm{CHD}$ incidence in adulthood. ${ }^{6}$

In 2015, we did a pilot project on screening/early detection of 370 fourth-grade-elementary students in Yogyakarta City using 12 leads electrocardiogram (ECG). Implementation in the field showed that the screening method by using 12 leads ECG was well received by the students and their parents, and also considerably easy to perform. However, our team did this project independently, while a national screening system will require collaboration between many sectors. Therefore, this screening program should be tested on a larger scale and involve other stakeholders such as the government. The main purpose of this study is to test and assess congenital heart disease screening methods based on electrocardiography and heart auscultation, which are simple, effective and applicable to be performed on elementary school level.

\section{Methods}

\section{STUDY DESIGN}

A descriptive study was conducted to analyze the application of screening methods for CHD based on cardiac auscultation and 12-lead electrocardiography and to determine the prevalence of CHD on first grade elementary school students in Special Province of Yogyakarta. This pilot study was first initiated in 2015 and was conducted at three elementary schools in Yogyakarta City. 
The long-term purpose of this study was to implement a simple but reliable screening method to detect CHD on school-age children in Indonesia, by cardiac auscultation and 12-lead electrocardiography examination, and incorporate it with the currently prevailed school-age health screening. In detail, we aimed at:

- Implementing simple and reliable CHD screening methods based on cardiac auscultation and 12lead electrocardiography in school-age children

- Determining prevalence of CHD in school-age children

- Validating CHD screening method based on cardiac auscultation and 12-lead electrocardiography by broad regional involvement.

- Incorporating CHD screening method based on cardiac auscultation and 12-lead electrocardiography to the National Health Care program.

- Reducing morbidity and mortality caused by undetected $\mathrm{CHD}$ in adults.

\section{TARGET POPULATION}

The study aimed to perform examinations on school-age children. Currently, one of many focuses of the Indonesian Ministry of Health is child health. One of their programs is health screening which is done on first year elementary school students. Examinations on eye, ear, nose, and throat are commonly performed with measurement of height and weight during health screening. Health personnel with other trained personnel conduct these examinations. Health personnel mentioned are medical personnel, nurses or other clinical staff who had been trained as specialized personnel for Health School Program (Unit Kesehatan Masyarakat (UKS)).

In Japan, a series of CHD screening in children are done at many levels of age group. This method was also considered during our discussion with stakeholders. After a series of discussions were held between our team and the government offices, it was concluded that the congenital heart disease screening program should be integrated with the current screening program of elementary school students. Therefore, first-year students were chosen for this study. No exclusion criteria were applied. All first-year students of selected elementary schools were eligible for examination, without attention to any prior signs and symptoms.

\section{STUDY AREA AND SAMPLING FRAME}

Purposive sampling was done on elementary schools and primary health centers in Yogyakarta Province. There are five districts (four regencies and one municipality) with 78 sub-districts in Yogyakarta and populated by $3,631,015$ people. Of these 738,700 were school-age children (Figure 1). Based on data of Provincial Education, Youth and Sport Office in 2017, there were 46,929 first-year elementary students of 
1,840 schools. Each of the 78 sub-districts usually has one or two community/primary health centers in the area and every primary health center is usually responsible for more than three elementary schools.

Distribution of number of schools chosen per districts was based on 2017 data of total students, while health centers selection was based on performance and recommendations by the district health office. For the first year of this study in 2018, we selected 45 schools from 19 community health centers with approximately 3000 first year students. In the second year, in 2019, 85 schools were selected from 53 community health centers with approximately 4000 students. The number of schools and health centers was doubled by the second year as with aiming to train more health workers and socialize this program to wider audience.

\section{PILOT PHASE}

In mid 2015, we held a pilot study at three elementary schools in Yogyakarta. Around 370 students of grade 3 and 4 were recruited. At this stage, we recruited elementary students of year 3 and 4 considering the age of the students at this group were more likely to cooperate. Primary screening on CHD with 12 lead electrocardiography (ECG) examination was conducted at perspective schools. During the pilot program, with supervision of collaborator researchers from Kobe University, Japan, students showed high enthusiasm and were not afraid nor embarrassed with the screening examinations. Furthermore, time needed to perform the primary screening on each student was not as long as expected. We examined 370 students during the primary screening by performing physical examination and ECG. Of those, 5 students were found with abnormal heart sounds and 45 with abnormal ECG readings. Of those students, 23 were examined during the secondary screening by using transthoracic echocardiography (others were lost to follow up or declined). Thereafter, we confirmed 1 student with Ventricular Septal Defect. This student was later referred to a pediatric cardiology consultant for further treatment.

\section{EXAMINATION PROCEDURE}

The CHD screening method which was initiated consists of two stages, primary and secondary screening. Primary screening is examination on first grade elementary students using physical examinations focusing on heart auscultation and 12-lead electrocardiogram (ECG). The 12-lead ECG is made up of three standard limb leads (I, II, III), three augmented limb leads (aVR, aVL and aVF) and six precordial leads (V1, V2, V3, V4, V5, V6). Secondary screening is further examinations on students that showed abnormal ECG reading from primary screening. At this stage, physical diagnostic heart examination (inspection, percussion, palpation, and auscultation using cardiology stethoscope), confirmative 12 lead ECG, and definitive echocardiography are performed.

The 12-lead ECG and physical heart examination was done by general physicians from primary health centers who had been trained to use a standard method. Interpretations of the ECG reading were categorized into normal and abnormal. A cardiologist or pediatric cardiologist then confirmed the 
abnormal ECG readings that were found. The suspected students with positive heart murmurs and/or confirmed abnormal ECG readings was then brought to hospital in their respective districts to go through secondary screening by another cardiologist or pediatric cardiologist.

\section{Results}

In this study, collaborations with local government were established. We worked with the Provincial Health Office, Education, Youth, and Sport Office, community/primary health centers, and elementary schools for the course of this program. Currently, the examinations have not yet been finished. A total 130 elementary and 60 community/primary health centers from 5 districts of Yogyakarta Province were recruited in the two years period. Twelve primary health centers participated at the first and second year periods. The purpose was not only to train more health workers from other primary health centers on the second year, but also to have the first batch accustomed with the screening program.

Examinations in CHD primary screening took approximately 5 minutes per student, without combining other health examinations. The majority of the students who were examined were shown to be easy to cooperate and did not make any considerable disturbances. Nevertheless, a few of them still refused and were scared by the ECG.

During preparations for the primary screening, we found that provision of logistics and number of health personnel of each primary health centers differed from one to another. Most of them only have one ECG, and with different conditions. The common case was the only ECG could not be brought outside the health center, as it was used during health care services. While others had reported that their ECGs were deemed unusable. Additionally, a number of primary health centers had limited health personnel, in which they were not able to merge ECG examination into the current health screening due to lack of human resources. However, there were still primary health centers that independently proceeded with the primary screening without any problems.

\section{A number of students were found with abnormalities at the primary screening. These students were later referred to a hospital for secondary screening.}

\section{Discussion}

Birth prevalence of $\mathrm{CHD}$ is similar worldwide, currently estimated at 10 to 12 per 1,000 live births. ${ }^{14}$ Early detection is important not only to provide optimal therapy, but also prevent further complications. CHD can be categorized into two groups, cyanotic and non-cyanotic CHD. Cyanotic CHD can be easily detected since birth and childhood, while non-cyanotic CHD can be asymptomatic or with minimal symptoms which can be undetected until complications manifest. 
In developed countries, such as Japan, many methods of heart disease screening have been established which are conducted during various stages of children's growth. ${ }^{5,6,15}$ Screening of CHD does not need sophisticated tools, since by utilizing simple equipment it is still possible to find suspected CHD patients. One of the most effective methods is by using fetal ECG, which is able to visualize the fetal heart during pregnancy, thus early detection of a congenital heart anomaly can be done. ${ }^{16}$ In Indonesia, it is mandatory for pregnant women to have at least three ultrasonography (USG) examinations during antenatal care. Once during early pregnancy, to determine gestational age, fetal viability, number and positions of the fetus, as well as detection of any major fetal abnormality. Then, next is at 20 weeks of pregnancy, to detect fetal abnormality, followed by USG examination during the third trimester to prepare for labor. Sadly, in Indonesia many pregnant women do not go through all examinations due to various reasons, such as financial problem, no experienced health provider in the area, and customary beliefs. Thus, many fetuses with a congenital anomaly are left undiagnosed until birth or later as adults.

In the United States, toolkits or guidelines on CHD screening have been published. The Children's National Medical Center published a screening toolkit on critical CHD. This guideline recommends the use of pulse oximetry in newborns to identify critical $\mathrm{CHD}$, a more serious form of $\mathrm{CHD}$ that requires intervention in the first year of life. It is also mentioned in the guidelines that detection of heart defect during postnatal period, which is currently done based on symptoms and physical examination within the first 24 hours of life, was proven to effectively have found only $50 \%$ of infants with heart defects. Nevertheless, pulse oximetry could help identify newborns or infants with low levels of oxygen and help make faster diagnosing of critical CHD. ${ }^{5}$

Other methods have also been developed such as heart auscultation examination with stethoscope, 12 lead electrocardiogram, peripheral saturation examination using pulse oximetry while resting and after activities, heart exercise examination, and ECG. In Japan, these examinations are being done at many stages of child growth, from fetus until secondary school. The screening system has been conducted in Japan from 1995 and has been proven to significantly reduce sudden death within school settings. Thus, these methods should be considered in Indonesia. ${ }^{6}$

In Indonesia, child health has been one of the top priorities of the Ministry of Health. Programs have been done in maintaining infant and child health that must be addressed to prepare healthy, intelligent, and good quality future generations and to reduce infant and child mortality. The programs are conducted since the fetus was still in the womb, at birth, after birth, and until the age of 18 (eighteen) years. Programs in school-age levels are school health programs for elementary school and adolescences healthcare. According to the Ministry of Health, school-age children are strategic targets for health program implementations, because they are large in numbers and also accessible because they are well organized. Programs for older children or adolescences focus more on improving skills and knowledge in health education, such as appointment of Young Doctors (Dokter Kecil) and Adolescences Healthcare. For younger children, mainly first year elementary students, health screening or medical examination is done every year, usually at the beginning of the new school term. However, the current screening does not involve examination on cardiac health. 
This study aimed to find possibilities to implement and incorporate heart screening for children in Indonesia with the current health screening and find prevalence of congenital heart disease by using ECG. Teams from primary health cares performed examinations of primary screening, and each team consisted of health personnel, which were general practice doctor(s) and nurse(s). The primary screening was performed concomitant with yearly medical examinations for first grade elementary school. Negative evaluations on the implementation of the primary screening are mainly due to lack of resources, either human resources or logistics. Nevertheless, the primary CHD screening was feasible and considerably easy to perform and was able to diagnose children with suspected heart abnormalities.

There are possibilities of bias and subjectivity that can affect the outcomes of this study. Previous study on primary physicians or general practioners' skills on pediatric cardiac auscultation showed low performances independent of training levels. ${ }^{17}$ Therefore, possibilities of under or over diagnoses of heart murmurs could have happened during primary screening. Additional trainings on heart auscultation prior to primary screening for primary health care doctors who would perform the heart murmur examinations are needed to improve their performance.

\section{Conclusions}

This study is the first screening program that focuses on heart diseases in elementary school students in Indonesia. It showed that it is possible to perform CHD screening on elementary school students in Yogyakarta Province using 12-lead electrocardiograph. ECG and heart sound examinations can be used as primary screening to find suspected children with heart abnormalities. The success and feasibility of this program will give a valuable impact on preventing CHD complications during adulthood. However, improvement of human resources and logistics availability are of considerable importance in order for the government to successfully perform heart disease screening on elementary school children. To establish the sustainability of this heart-screening program, the cost-effectiveness of the needs to be assessed, independently.

\section{Abbreviations}

\section{ASD: Atrial Septal Defect}

\section{CHD: Congenital Heart Disease}

\section{COHARD-PH: Congenital HeARt Disease-Pulmonary Hypertension}

\section{ECG: Electrocardiography}

\section{PAH: Pulmonary Arterial Hypertension}




\section{PDA: Patent Ductus Arteriosus}

\section{UKS: Unit Kesehatan Sekolah}

\section{USG: Ultrasonography}

\section{VSD: Ventricle Septal Defect}

\section{Declarations}

\section{Ethics approval and consent to participate}

This study was approved by Medical and Health Research Ethics Committee, Faculty of Medicine, Public Health and Nursing, Universitas Gadjah Mada-Dr.Sardjito General Hospital in Yogyakarta Province, Indonesia. Written inform consent was obtained from parents/student guardians of participants.

\section{Consent for publication}

\section{Not applicable.}

\section{Avaibility of data and material}

The raw data and data set used to support the findings of this study have not been made available because of the confidentiality policy in our department and ongoing research. However, authors are open to any discussions regarding the dataset availability within reasonable request.

\section{Competing Interests}

\section{All authors declare that they have no competing interests.}

\section{Funding}

This study was funded by Penelitian Dasar Unggulan Perguruan TInggi (PDUPT) Grant from The Ministry of Research, Technology, and Higher Education, Republic of Indonesia, on 2018 (53/UN1/DITLIT/DITLIT/LT/2018) and 2019 (2609/UN1.DITLIT/DIT-LIT/LT/2019) (Principal Investigator: Lucia Kris Dinarti). There was no role of the funding body in the design of the study and collection, analysis, and interpretation of data and in writing the manuscript. 


\section{Authors' Contributions}

LKD, $A B H, I K M$, and DWA initiated the registry, conceptualized the study outline, drafted and revised the manuscript. AP, VCD, and MRH collected data, maintain communications with stake holders and drafted the manuscript. All authors have read and approved the final manuscript.

\section{Acknowledgements}

The authors would like to thank Prof. Noriaki Emoto from Kobe University, Japan for his collaboration during the screening projects. Mrs. Pembajun Setyaningastitie as the Head of Public Health Office of Yogyakarta Province for her facilitation and discussion regarding the implementation of the screening program; Prahesti Fajarwati, MD from Public Health Office of Yogyakarta Province for her discussion regarding the implementation of the screening program, and Mrs. Lutfiah from Education, Youth, and Sport Office of Yogyakarta Province for her facilitation and discussion regarding the data of elementary school in DIY.

\section{References}

1. Luc-Bernier, P., Stefanescu, A., Samoukovic, G., Tchervenkov, I. 2010. The challenge of congenital heart disease worldwide: epidemiologic and demographic facts. Ped Cardiac Surg Ann, 13:26-34. 2. Pierpont, M. E., Basson, C. T., Benson, D. W. Jr., Gelb, B. D., Giglia, T. M., Goldmuntz, E. 2007. Genetic basis for congenital heart defects: current knowledge: a scientific statement from the American Heart Association Congenital Cardiac Defects Committee, Council on Cardiovascular Disease in the Young: endorsed by the American Academy of Pediatrics. Circulation, 115: 3015-3038. 3. Braunwald, E., Zipes, D.P., Libb, P. 2001. Braunwald Heart Disease: A Textbook of Cardiovascular Medicine. 6th ed. WB Saunders: Philadelphia. 4. Webb, G.D., Smallhorn, J.F., Therrien, J. 2007. Congenital heart disease. In: Libby P, Bonow R, Mann D, editors. Braunwald's Heart Disease: A Text-book of Cardiovascular Disease. 8th edition. Philadelphia, PA: Saunders. 5. Chamsi-Pasha, M. \& Chamsi-Pasha, H., 2016. Critical congenital heart disease screening. Avicenna Journal of Medicine, 6(3), p.65. 6. Kato, T. et al., 2018. Guidelines for Heart Disease Screening in Schools (JCS 2016/JSPCCS 2016) - Digest Version - . Circulation Journal, 82(9), pp.2385-2444. 7. Gelernter-Yaniv, L., Lorber, A. 2007. The familial form of atrial septal defect. Acta Paediatr,96:726-30. 8. Salehian, O., Horlick, E., Schwerzmann, M., Haberer, K., McLaughlin, P., Siu, S.C., Webb, G., Therrien, J. 2005. Improvements in cardiac form and function after transcatheter closure of secundum atrial septal defects. J Am Coll Cardiol, 45: 4. 9. Duffels, M.G., Engelfriet, P.M., Berger, R.M., Van Loon, R.L., Hoendermis, E., Vriend, J.W., Van Der Velde, E.T., Bresser, P., Mulder, B.J. 2007. Pulmonary arterial hypertension in congenital heart disease: an epidemiologic perspective from a Dutch registry. Int $\mathrm{J}$ Cardiol, 120: 198-204. 10. Engelfriet P.M., Duffels M.G., Moller T., Boersma E., Tijssen J.G., Thaulow E., Gatzoulis M.A. \& Mulder B.J. 2007. Pulmonary arterial hypertension in adults born with a heart septal defect: The Euro Heart Survey on adult congenital heart disease. Heart, 93: 682-7. 11. Gabriels C., De Meester P., Pasquet A., De Backer J., Paelinck B.P., Morissens M., Van De Bruaene A., Delcroix M. \& Budts 
W. 2014. A different view on predictors of pulmonary hypertension in secundum atrial septal defect. Int $\mathrm{J}$ Cardiol, 176: 833-840. 12. Geva, T., Martins, J.D., Wald, R.M. 2014. Atrial septal defects. Lancet, 383: 19211932. 13. Krisdinarti, L., Hartopo, B.H., Anggrahini, D.W., Sadewa, A.H., Wahab, A.S., Setianto, B.Y. 2016. Clinical characteristics of adult uncorrected secundum atrial septal defect: a pilot study. J Med Sci, 48(2): 89-97. 14. Staveski, S.L. et al., 2017. The global burden of paediatric heart disease. Cardiology in the Young, 27(S6), pp.S3-S8. 15. Naiman, R.A. \& Barrow, J.G., 2012. Heart disease screening in school children. Circulation, 29(5), pp.708-712. 16. Van Velzen, C.L. et al., 2016. Prenatal detection of congenital heart disease - Results of a national screening programme. BJOG: An International Journal of Obstetrics and Gynaecology, 123(3), pp.400-407. 17. Germanakis, I. et al., 2013. Skills of primary healthcare physicians in paediatric cardiac auscultation. Acta Paediatrica, International Journal of Paediatrics, 102(2), pp.74-78.

\section{Figures}

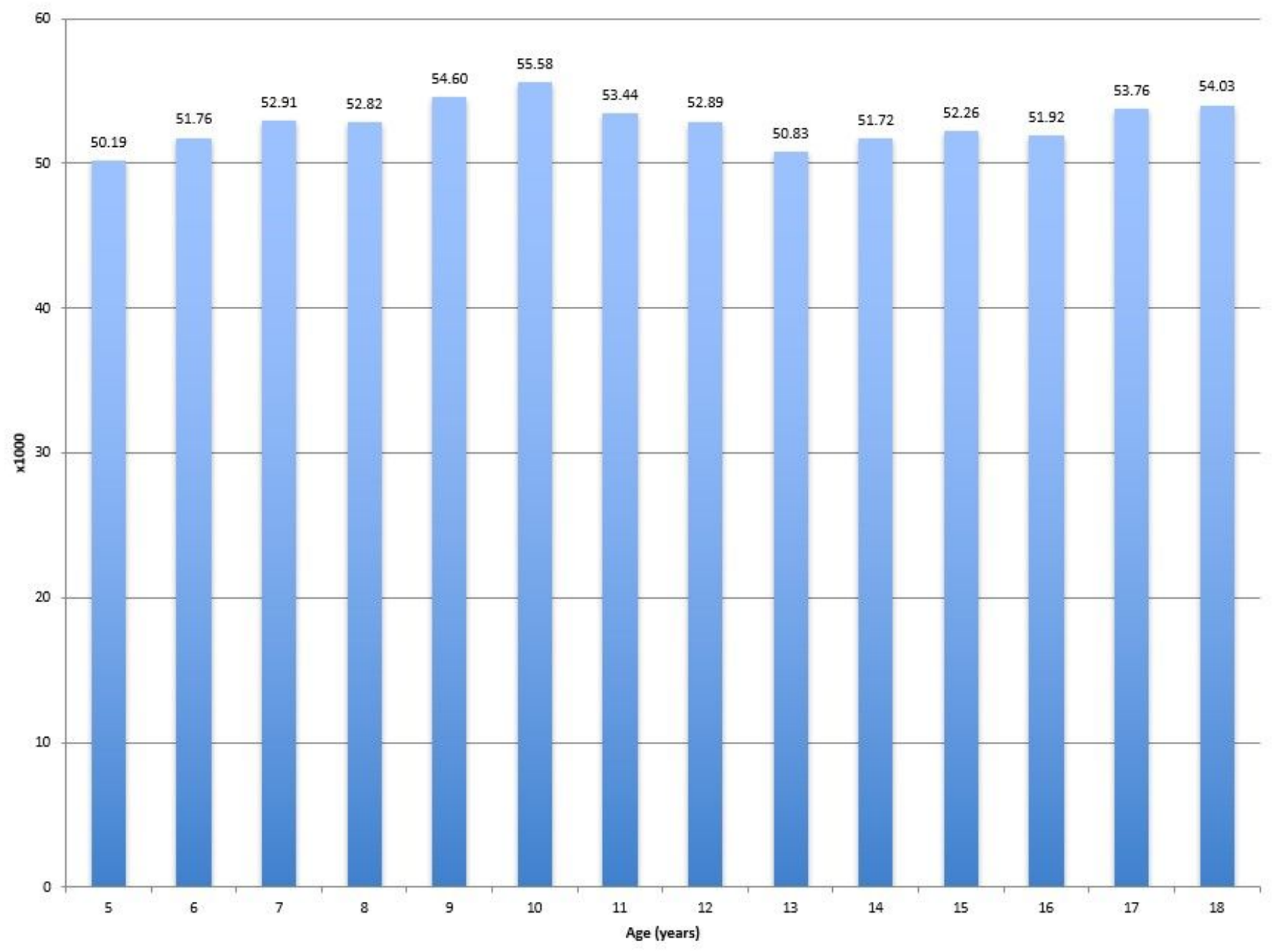

Figure 1 
Number of school-age children in Yogyakarta Province in 2018

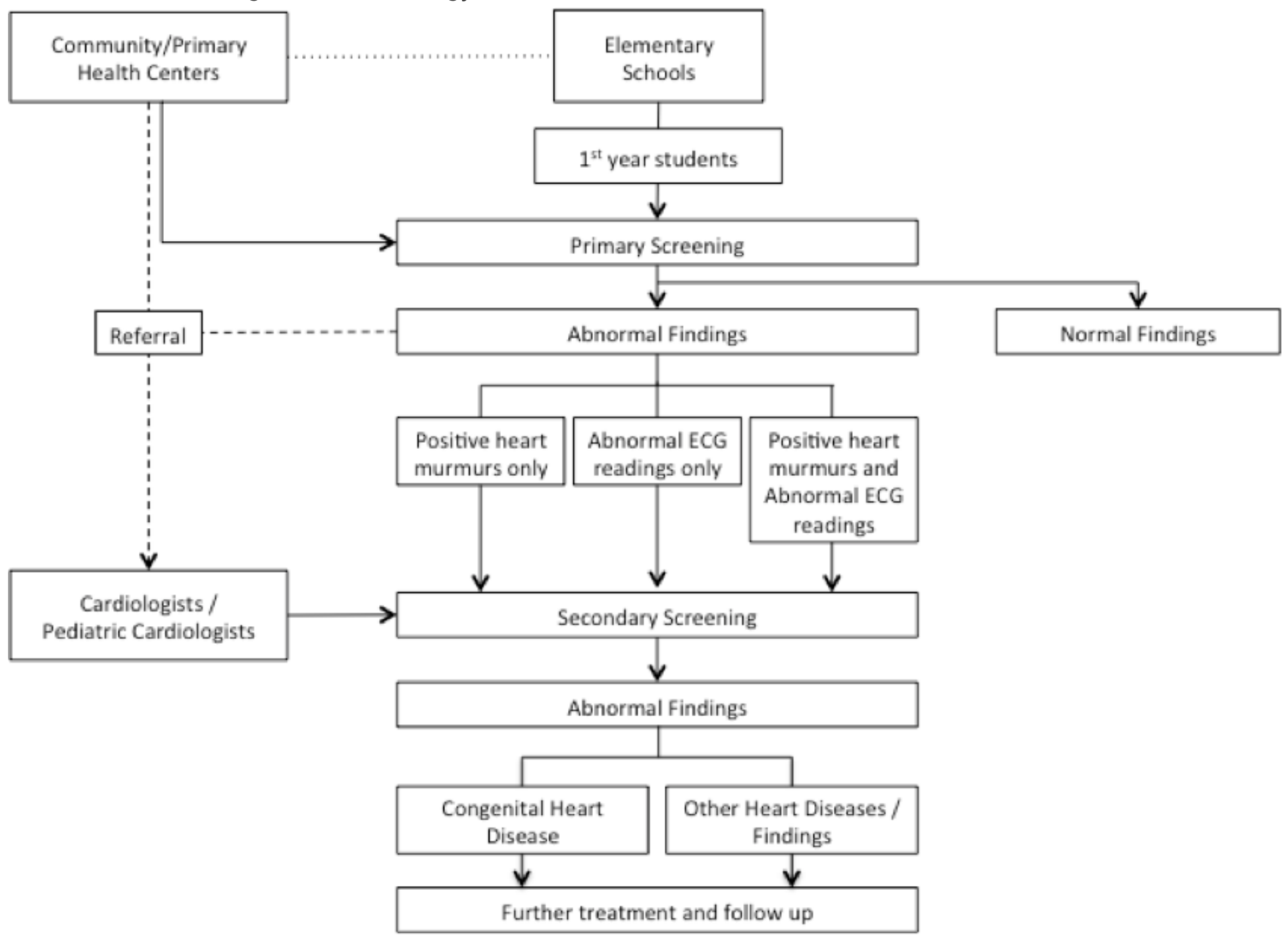

Figure 2

Screening algorithm for this study 